\title{
A health technology assessment between two pharmacological therapies through Six Sigma: the case study of bone cancer
}

Health technology assessment through Six Sigma

\author{
Carlo Ricciardi
}

Department of Advanced Biomedical Sciences, Università degli Studi di Napoli Federico II, Napoli, Italy

Alfonso Sorrentino

Maxillofacial Surgery Unit, Department of Neurosciences, Reproductive and Odontostomatological Sciences, Federico II University Hospital, Napoli, Italy

Giovanni Improta

Department of Public Health, Università degli Studi di Napoli Federico II, Napoli, Italy

Vincenzo Abbate

Maxillofacial Surgery Unit, Department of Neurosciences, Reproductive and Odontostomatological Sciences, Federico II University Hospital, Napoli, Italy Imma Latessa

Department of Public Health, Università degli Studi di Napoli Federico II, Napoli, Italy

Antonietta Perrone

Service of Clinical Engineering, Health Technology and HTA, Federico II University Hospital, Napoli, Italy

Maria Triassi

Department of Public Health, Università degli Studi di Napoli Federico II, Napoli, Italy, and

Giovanni Dell'aversana Orabona

Maxillofacial Surgery Unit, Department of Neurosciences, Reproductive and Odontostomatological Sciences, Federico II University Hospital, Napoli, Italy

\begin{abstract}
Purpose - Head and neck cancers are multi-factorial diseases that can affect many sides of people's life and are due to a lot of risk factors. According to their characteristics, the treatment can be surgical, use of radiation or chemotherapy. The use of a surgical treatment can lead to surgical infections that are a main theme in medicine.
\end{abstract}

(c) Carlo Ricciardi, Alfonso Sorrentino, Giovanni Improta, Vincenzo Abbate, Imma Latessa, Antonietta Perrone, Maria Triassi and Giovanni Dell'aversana Orabona. Published by Emerald Publishing Limited. This article is published under the Creative Commons Attribution (CC BY 4.0) licence. Anyone may reproduce, distribute, translate and create derivative works of this article (for both commercial and non-commercial purposes), subject to full attribution to the original publication and authors. The full terms of this licence may be seen at http://creativecommons.org/licences/by/4.0/legalcode

Funding: the authors received no funding.

Conflict of interests: the authors declare they have no conflict of interests.

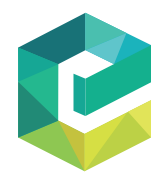

Received 24 January 2020 Revised 30 April 2020 Accepted 24 May 2020 
TQM 32,6

At the University hospital of Naples "Federico II", two antibiotics were employed to tackle the issue of the infections and they are compared in this paper to find which one implies the lowest length of hospital stay (LOS) and the reduction of infections.

Design/methodology/approach - The Six Sigma methodology and its problem-solving strategy DMAIC (define, measure, analyse, improve, control), already employed in the healthcare sector, were used as a tool of a health technology assessment between two drugs. In this paper the DMAIC roadmap is used to compare the Ceftriaxone (administered to a group of 48 patients) and the association of Cefazolin plus Clindamycin (administered to a group of 45 patients).

Findings - The results show that the LOS of patients treated with Ceftriaxone is lower than those who were treated with the association of Cefazolin plus Clindamycin, the difference is about $41 \%$. Moreover, a lower number of complications and infections was found in patients who received Ceftriaxone. Finally, a greater number of antibiotic shifts was needed by patients treated with Cefazolin plus Clindamycin.

Research limitations/implications - While the paper enhances clearly the advantages for patients' outcomes regarding the LOS and the number of complications, it did not analyse the costs of the two antibiotics. Practical implications - Employing the Ceftriaxone would allow the Department of Maxillofacial Surgery to obtain lower LOS and a limited number of complications/infections for recovered patients, consequently reducing the hospitalization costs.

Originality/value - There is a double value in this paper: first of all, the comparison between the two antibiotics gives an answer to one of the main issues in medicine that is the reduction of hospital-acquired infections; secondly, the Six Sigma through its DMAIC cycle can be employed also to compare two biomedical technologies as a tool of health technology assessment studies.

Keywords Health technology assessment, Six sigma, DMAIC, Public health, Healthcare, Drugs

Paper type Research paper

\section{Acronyms}

$\begin{array}{ll}\text { AHP } & \text { Analytic Hierarchy Process; } \\ \text { CTQ } & \text { Critical to Quality; } \\ \text { DMAIC } & \text { Define, Measure, Analyse, Improve, Control; } \\ \text { HTA } & \text { Health Technology Assessment; } \\ \text { LOS } & \text { Length of Hospital Stay; } \\ \text { SIPOC } & \text { Suppliers, Inputs, Process, Outputs, Customers; } \\ \text { SS } & \text { Six Sigma; } \\ \text { SSI } & \text { Surgical Site Infections. }\end{array}$

\section{Introduction}

Head and neck cancers are referred to those malignant tumoral pathologies that can occur in a district that comprehends the skull and the neck from the lower edge of the jaw until the upper edge of the clavicles. Because of the involvement of the face and the neck, these kinds of cancers can affect several important biological functions such as breathing, talking and swallowing depending on the different anatomical parts where the primary tumor is located (Lester et al., 2012). The development of head and neck cancers is multi-factorial and is related to several etiological factors called "risk factors"; the most common are smoking (Khan et al., 2014), alcohol abuse (Hashibe et al., 2009; Chuang et al., 2012), mucosal inflammatory disease due to trauma (Rotundo et al., 2013) or infections (Ribeiro et al., 2011; Sammam et al., 2014; Saulle et al., 2015), precancerous lesions (Tachezy et al., 2009; Radoi et al., 2013) and poor oral hygiene. Risk factors can work alone or in a synergistic manner (Hashibe et al., 2009). Head and neck cancers are generally associated to a bad prognosis due to the delicate region that affects. The head and neck district in fact is a very important anatomical region that allows many physiological functions. Also, the aesthetic aspect is important when talking about head and neck cancers, due to the district where this kind of malignant tumor arises. Oncologic maxillofacial surgery is that branch of maxillofacial surgery which deals with the surgical approach to head and neck malignancies and the reconstruction of the lost tissues. Among head and neck cancers, oral squamous carcinoma is one of the most common cancers of the face and the most common of the 
mouth. It represents alone the $90 \%$ of the malignancies of the oral cavity [1] (Chaturvedi et al., 2013). Patients undergoing head and neck cancers surgery develop infections in $20-50 \%$ of cases (Karakida et al., 2010; Kamizono et al., 2014; Ogihara et al., 2009). This percentage increases when cancer surgery is performed in the mouth because of the presence of resident and nonresident bacteria (Durand et al., 2015). These infections, best known as surgical site infections (SSIs), occur within the first 30 postoperative days. They are influenced by multiple variables such as age, oral health, related diseases, smoking and alcohol habits, cancer pathology, the presence of tracheostomy and the kind of surgery (Ogihara et al., 2009). Regarding the area of surgery, commonly several authors used prophylactic antibiotics targeting normal oral flora (Karakida et al., 2010; Horan et al., 1992). Some studies suggest that surgical sites can be colonized also by non-normal oral flora (Becker et al., 1978). This is because, for major surgeries and big tissue removal, a reconstruction of the surgical site with local flaps or micro vascular flaps coming from different parts of the body is required (Garnier et al., 2013a, b). This leads to the infection of surgical wounds by non-resident microflora that need a good antibiotic approach to prevent surgical complications, such as SSIs. They may appear as infections, dehiscence, fistulae and abscess that may compromise the success of the surgery and increase the length and the costs of the hospitalization. Even though many studies have been conducted, now there is not a universal antibiotic prophylactic protocol that can be used to prevent SSIs (Russel et al., 2012).

In the Department of Maxillofacial Surgery of the University of Naples "Federico II", from 2006 to 2019, two different antibiotic protocols were used in patients who underwent oral cancer surgery on bone tissues, according to scientific guidelines. When no allergy was described from 2006 to 2011, a postoperative antibiotic protocol with Ceftriaxone was used. From 2011, there was a shift to the use of the association of Cefazolin plus Clindamycin as postoperative prophylactic protocol.

On the one hand, the Health Technology Assessment (HTA) allows health policy to analyse and assess health technologies, taking into account all medical-clinical, organizational, economic, social, legal and ethical implications, both directly and indirectly caused and both short- and long-term implications (Battista et al., 1999; Favaretti et al., 2009). On the other hand, Six Sigma (SS) was originally a concept for company-wide quality improvement introduced by Motorola in 1987. The term sigma, used by statisticians, defines the standard deviation of a random variable, that is, the oscillation of a parameter than average. A number of times of sigma indicates the number of defects that are likely to occur in a given (production or service) process. In particular, the more sigma there are, the more stable the process is and therefore less subject to variance. A three-sigma process, for example, has a defect rate of $6.7 \%$, while a six-sigma process has only 3.4 defects per million opportunities. Achieving processes at SS level symbolizes the systematic pursuit of breakthroughs. Defects cause an increase in costs and SS reduces costs by reducing the number of defects (Van Den Heuvel et al., 2005). It is deployed by carrying out improvement projects, and to secure a successful launch and deployment of SS, an organizational infrastructure is created. For example, a deployment plan for strategically relevant projects ensures an alignment of project goals with the long-term organizational objectives. Furthermore, SS uses a stage-gate approach to project management whereby projects are monitored carefully by champions, and appropriate actions are taken if a project does not meet specified completion dates (Koning et al., 2006). It involves detailed plans that help to guide project leaders through the execution of the quality improvement project.

In literature, some researchers focussed on the study of drugs through the SS methodology: Lee Steere et al. investigated intravenous device-related practices through define, measure, analyse, improve, control (DMAIC) problem-solving strategy (Steere et al., 2018), and Vrijens et al. proposed an SS framework to reduce the issue of medication non-adherence (Vrijens, 2019). Kuwaiti and Subbarayalu et al. tried to reduce the hospital-acquired infections during the catheter-related bloodstream infections employing DMAIC cycle and suggested someone deals with antibiotic prophylaxis in surgery (Al Kuwaiti and Subbarayalu, 2017). Similarly, Montella 
TQM

32,6

1510 et al. reported on the implementation of the Lean Six Sigma method to reduce the number of patients affected by sentinel bacterial infections (Montella et al., 2017).

As such, the aim of this work is to assess the efficacy of two antibiotics (Cefazolin/ Clindamycin and Ceftriaxone) on the outcome of patients undergoing oral and maxillofacial surgery at the University hospital of Naples "Federico II" using the SS methodology and its problem-solving strategy DMAIC as a preference elicitation method in HTA just like Danner et al. and Improta et al. have done with the analytic hierarchy process (AHP) (Danner et al., 2011; Improta et al., 2019b). Postoperative length of hospital stay (LOS) will be the main indicator to assess the improvements brought by the new antibiotic quantitatively.

\subsection{Literature review: Six Sigma}

Decision-making methods, software and simulation approaches and modern quality management tools such as the SS concept offer realistic solutions to reach practical levels of perfection in the healthcare, by helping the assessment of technologies with HTA studies (Improta et al., 2019b), elaboration and simulation of complex data (Converso et al., 2015; Improta et al., 2018c; Romano et al., 2018), the implementation of machine learning algorithms (D'Addio et al., 2020; Recenti et al., 2020) and the improvement of process performances (Fillingham, 2008; Improta et al., 2018b).

Firstly, the SS was used in the manufacturing sector: Adikorley et al. applied it in the textile industry (Adikorley et al., 2017) while Besseris et al. made an application in the food industry (Besseris et al., 2014). Many researchers have conducted systematic review to explore the methodology from different perspectives: Bakar et al. reviewed all the critical factors of success of the methodology (Bakar et al., 2015) while, recently, Chugani et al. investigated the application of this methodology from a green research perspective (Chugani et al., 2017), Freitas et al. studied the impact of the methodology on the organizational sustainability (Freitas et al., 2017) and Walter and Paladini identified the main directions for future research (Walter and Paladini, 2019).

Both SS and DMAIC cycle have been used to address numerous problems in the health sector, including decreasing LOS, reducing medication errors and improving the admissions process (Allen et al., 2009; Feng and Manuel, 2008; Van Den Heuvel et al., 2006). Here, some examples are reported from the most recent literature (from 2014 to 2019) about the applications of SS and DMAIC in healthcare.

In 2014, Sahbaz et al. used SS to reduce complications during and after laser-assisted surgeries in a private eye care centre in Turkey. They adopted the DMAIC approach and tools and concluded that 16 complications (out of 17) should be significantly reduced by taking the necessary preventive measures (Şahbaz et al., 2014). In the same year, Vijay adopted the SS and DMAIC methodology to improve the hospital discharge process in a multidisciplinary hospital setting in India, achieving a $61 \%$ reduction in the cycle time of patient discharge process and the implementation of a control plan to sustain the improvements obtained (Vijay, 2014).

Another application of SS to improve the patient discharge process was published by El-Eid et al., 2015. They proposed a quantitative pre- and post-intervention study over a ten-month period and decreased the discharge time by $22.7 \%$ from $2.2 \mathrm{~h}$ during the preintervention period to $1.7 \mathrm{~h}$ post-intervention, confirming SS as an effective change management tool to improve discharge time (El-Eid et al., 2015).

Reduced discharge time and LOS were also achieved by Improta $e t$ al. and Ricciardi $e t a l$, who proposed a new approach to the management of patients undergoing prosthetic hip replacement surgery at the Complex Operative Unit (UOC) of Orthopaedics and Traumatology of the University Hospital "Federico II" by combining Lean and SS methodologies and following the DMAIC cycle. The average patient LOS was reduced from 18.9 to 10.6 days (-44\%) (Improta et al., 2015; Ricciardi et al., 2020). Loftus $e$ al. successfully applied the DMAIC cycle to develop a 
solution to improve outcomes in a high-risk neurotrauma intensive care unit, managing to reduce and prevent central-line-associated bloodstream infections (Loftus et al., 2015).

In 2016, Ortiz Barrios et al. adopted the SS to reduce appointment lead time in obstetrics outpatient department, which can cause risk of severe complications in pregnant women. They used the SIPOC and fishbone diagram to define the problem and determine the possible causes. Other statistical tools, used to measure the process performances, showed that the average appointment lead time reduced from 6.89 days to 4.08 days (Barrios and Jiménez, 2016).

Kalra et al. showed the main problems occurring in the diagnostic clinical diagnostic laboratories and systematically explained the reasons why these laboratories should promote and develop a culture of safety with the aid of SS and DMAIC tools (Kalra and Kopargaonkar, 2016). The application of SS proved to be helpful also in the outpatient pharmacy unit. The case study of Al Kuwaiti analysed the effect of SS methodology through DMAIC in reducing medication errors in the outpatient pharmacy of King Fahd Hospital of the University, Saudi Arabia, showing a marked reduction of prescription/data entry errors from 56,000 to 5,000, thereby improving patient safety and the quality of healthcare (Al Kuwaiti, 2016).

Between 2017 and 2018, three studies of Improta et al. showed how the adoption of DMAIC tools could be effective in decreasing LOS for patients undergoing prosthetic knee replacement surgery (Improta et al., 2017), increasing the performance of emergency departments in terms of waiting times for hospitalized patients (Improta et al., 2018b) and reducing the risk of healthcareassociated infections in medicine department (Improta et al., 2018a). In the first case, DMAIC cycle, applied at the Complex Operative Unit of Orthopaedics and Traumatology of the University Hospital "Federico II", led to the identification of variables which affect the prolongation of the LOS and the implementation of remedial actions to improve the process of care. The adopted actions reduced the LOS by $42 \%$, from a mean value of 14.2 to 8.3 days. In the second case, Lean methodology was applied at the Emergency Department of the A. Cardarelli Hospital. After the implementation of remedial actions, a positive performance increase was observed at the Emergency Department, quantified as a percentage of hospitalized patients according to triage codes and waiting times. In the third case, DMAIC methodology, applied at the University Hospital "Federico II", proved to be a useful tool to identify those variables which influenced the risk of healthcare-associated infections and to implement corrective actions in order to improve performance in process of care. After the improve phase, a reduction in the number of patients colonized by sentinel bacteria was achieved, from a value of $0.36-0.19 \%$. In the following study of Al Kuwaiti and Subbarayalu, the effectiveness of DMAIC in reducing the risk of hospital-acquired infections was confirmed by showing an infection rate significantly reduced from 3.92 during the pre-intervention phase to 2.73 during the post-intervention phase (Al Kuwaiti and Subbarayalu, 2017). Moreover, Arafeh et al. combined SS and DMAIC with discrete event simulation to reduce patient discharge time in King Hussein Cancer Centre by $54 \%$ from $216 \mathrm{~min}$, thereby confirming again that understanding process dynamics and improving them through the DMAIC principles ensures a significant and sustainable impact on operations (Arafeh et al., 2018).

In 2019, Alhamali reviewed the success factors and benefits of SS implementation in hospitals, revealing 25 critical success factors (e.g. managerial, statistical and technical aspects) necessary in the implementation of SS and 20 benefits derived from SS's implementation, including various improvements in terms of the organizations' processes, financial performance and the quality of service (Alhamali, 2019). Furthermore, Improta et al. adopted Lean Six Sigma and DMAIC roadmap as the correct methodology to validate the benefits of a fast-track surgery protocol, introduced to improve quality associated with prosthetic hip replacement surgery at the Complex Operative Unit of Orthopaedic and Traumatology of the University Hospital "Federico II". The authors demonstrated the efficacy and efficiency of the novel protocol, reducing the average LOS from 10.66 to 7.8 days (-26\%) (Improta et al., 2019a). Similarly, other researchers studied the reduction of LOS in a Diagnostic Therapeutic Assistance Path in
Health technology assessment through Six Sigma

1511 
TQM 32,6

patients with femur fractures obtaining an average LOS reduction from 13.14 to 9.21 days (-29.9\%) (Ricciardi et al., 2019; Improta et al., 2019b). Finally, not only has SS already been used with other methodologies such as Lean Thinking, but it has also been employed with Agile methodology in healthcare (Improta et al., 2020).

\section{Methods}

The SS method offers a structured, analytic and logically sound approach to problem-solving, as well as a strong organizational framework for its deployment. To operationalize this problemsolving strategy, SS deploys five phases - define, measure, analyse, improve and control - that are rigorously followed whenever a problem, large or small, is approached (Koning et al., 2006):

(1) In the define phase, a charter is drafted that contains a definition of the project and may include a cost-benefit analysis. If the cost-benefit analysis meets the companyestablished thresholds, the charter will be accepted, and the project will continue through the DMAIC process.

(2) In the subsequent measure phase, baseline data are assembled, and the diagnosis is started in earnest. The problem is translated into quantifiable terms using critical-toquality (CTQ) characteristics.

(3) The analyse phase continues the diagnosis and involves an identification of possible causal relationships between inputs and the CTQs.

(4) After the diagnosis is completed, the team proceeds to the improve phase and suggests a solution to the problem.

(5) Finally, in the control phase, control systems are developed to ensure that improvements are maintained, and the new improved process can be handed over to the day-to-day operations staff.

\subsection{Context}

The Department of Maxillofacial Surgery of the University Hospital of Naples "Federico II" has 22 beds for stay and a day hospital and consulting activities. It is structured on two different levels: the first level, located at the ground floor, consists of acceptance office, an ambulatory, a day surgery ambulatory, the direction, the departmental library, the residency office and other medical offices. The second level, located at the first floor of the building, hosts the hospital ward with a total of nine rooms and 22 beds. On the first floor, acceding from the hospital ward, is located the operating block, consisting of two operating rooms. Minor surgeries are performed daily in the day surgical ambulatory. Day surgery in the maxillofacial department consists of the biopsies and asportation of neoplasms, tooth extractions, oral surgery; major surgeries are performed three times a week. Depending on the different kinds of surgeries, the two operating rooms work at different times. Surgeries can last $12 \mathrm{~h}$ or more, and this is exactly the case of head and neck cancers surgeries that consist of two different phases: the demolition one and the reconstructive one. Operating rooms function also for emergency with a 24 -h team ready to work in these cases.

\subsection{Define}

The first phase of DMAIC is the define, and here the team is organized together with the main points of the project such as the CTQ and the target. The team was composed of engineers with previous experience in Lean Thinking and SS projects, a biologist and clinicians. Then, a simple project charter was designed in order to obtain an easy document with the key points of the project. The main scope was to find the antibiotic that could reduce the postoperative LOS and, eventually, the complications; therefore, the postoperative LOS was also defined as the CTQ for this study. The timeline for the study went from the end of 2010 to the end of 
2018. The Department of Maxillofacial Surgery of the University of Naples "Federico II" and the head and neck cancer surgery on bone tissues were considered "In Scope" while all the other structures and interventions were considered "Out of Scope".

The final goal of the project is to find the antibiotic that reduces the postoperative LOS of patients undergoing maxillofacial surgery and their number of complications. In process improvement, it can be useful to employ a SIPOC (suppliers, inputs, process, outputs, customers) diagram to represent other key points of the process under examination:

(1) Supplier:

- University hospital "Federico II" of Naples;

- Clinical staff;

(2) Input:

- Needs of patients;

- Oncologic medicine;

(3) Process:

- Arrival at the hospital;

- Hospitalization;

- Surgery;

- Postoperative activities;

- Discharge;

(4) Output:

- Faster hospitalization;

- Better outcome for patients;

- Less postoperative complications;

(5) Customers:

- Patients;

- University Hospital "Federico II" of Naples.

\subsection{Measure}

Two groups of patients were analysed in this study: the first one was treated with Ceftriaxone between 2006 and 2011, while the second one was treated with Cefazolin plus Clindamycin between 2011 and 2019. Cefazolin group was composed of 54 patients while the other one of 51 patients. Data were collected by printed medical records. All the statistical tests were performed by employing IBMSPSS. Several inclusion and exclusion criteria were employed to collect data:

(1) Patients who underwent a day surgery were not included since their LOS would have been "forced" by the procedure;

(2) Patients with too many missing data were excluded since they would have compromised the analysis;

(3) Patients with a shift of antibiotic therapy during their hospitalization were not analysed but the number of them was recorded since it is a qualitative indicator of the failure of the treatment; 
TQM

32,6

1514

(4) Patients allergic to Cefazolin and Clindamycin or Ceftriaxone were excluded.

In order to make a complete analysis in the following phases, for each patient, seven variables were collected. The following are the considered surgical variables and complications:

(1) Kind of surgical procedure;

(2) Flap;

(3) Lymphadenectomy;

(4) Tracheotomy;

(5) Infections;

(6) Dehiscence;

(7) Fistulae.

After the exclusion of patients who had experienced a shift of antibiotic, the first group, treated with Ceftriaxone, was composed of 48 subjects while the second one, treated with Cefazolin/ Clindamycin, was composed of 45 subjects. People who experienced a shift in the antibiotic treatment during their hospitalization were not considered in the analysis, but the number of shifts per each group was 9 for Cefazolin/Clindamycin and 3 for Ceftriaxone. In order to

Figure 1.

Mean postoperative LOS for each category of the variables regarding Cefazolin/ Clindamycin
Figure 2.

Mean postoperative LOS for each category of the variables regarding Ceftriaxone
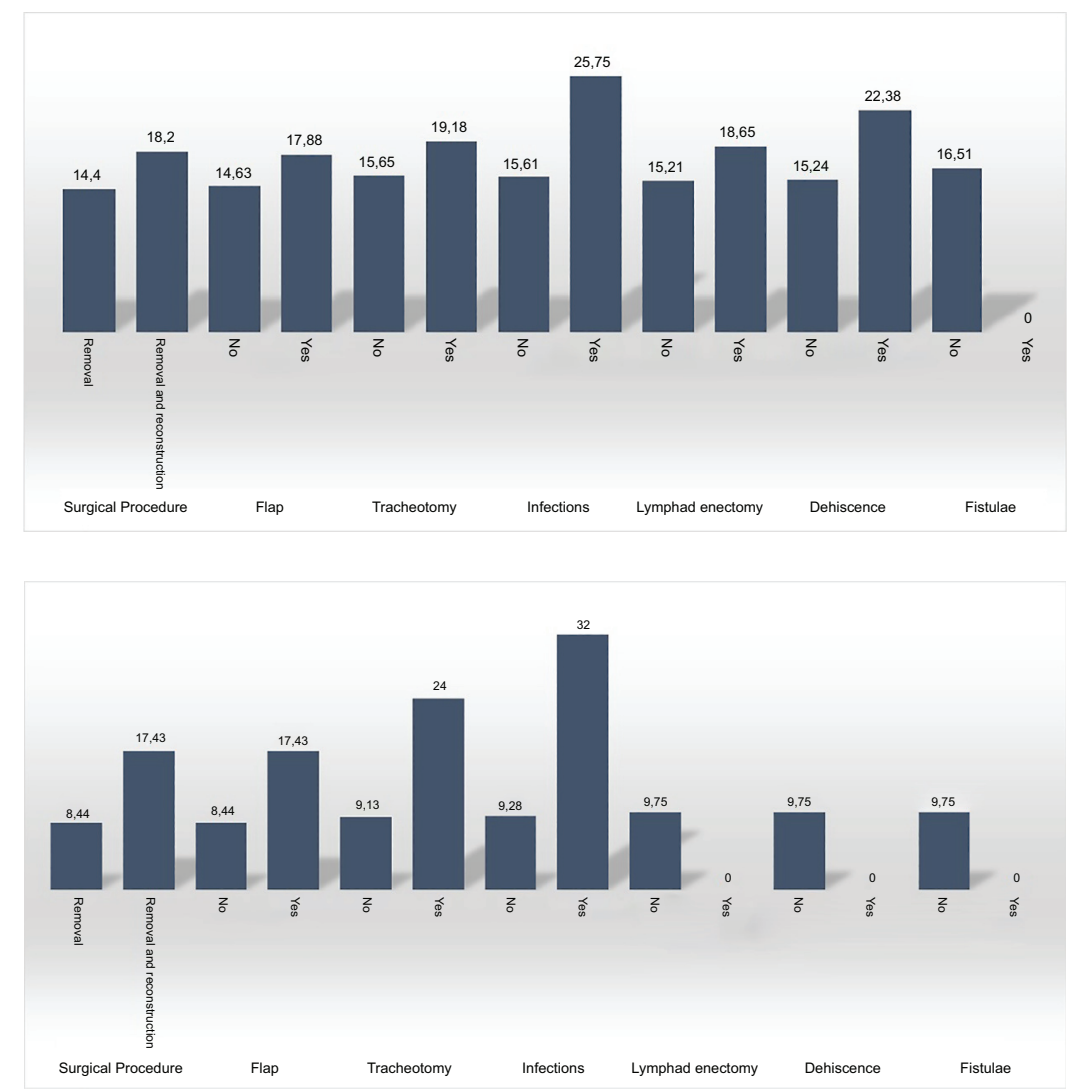
visualize graphically the mean values of postoperative LOS per each data set, Figure 1 and Figure 2 were drawn and represent the mean postoperative LOS of patients according to each category of all variables. A normality test (Kolmogorov-Smirnov) was applied to investigate the distribution of the postoperative LOS data with an alpha level of 0.05 .

The mean postoperative LOS of "Cefazolin/Clindamycin" group was 16.51 days with a standard deviation of 7.89 days while the "Ceftriaxone" group had a mean of 9.75 days with a standard deviation of 8.26 days.

\subsection{Analyse}

After the definition of the problem and the measurements in the previous sections to gain a better knowledge of the data set, the task is to analyse the process in both a qualitative and a quantitative way. First, a flow chart (Figure 3) was drawn to identify the main phases of the clinical process from the arrival of the patient to the hospital until the discharge.

The Kolmogorov-Smirnov test was applied to investigate the distribution of the postoperative LOS data regarding Cefazolin/Clindamycin, a $p$-value of 0.200 indicated a normality distribution. Thus, in order to investigate the variables potentially influencing postoperative LOS, $t$-tests were employed to compare the means (and standard deviations) of the categories of the variables. The results are represented in Table 1. Although the tests have not indicated a sufficiently low $p$-value, the differences between mean values of postoperative LOS in each category suggest that some variables could, effectively, influence LOS duration.

The same analysis was performed for the "Ceftriaxone" group. Kolmogorov-Smirnov

test showed a $p$-value lower than 0.0001; thus, a non-parametric test was employed:

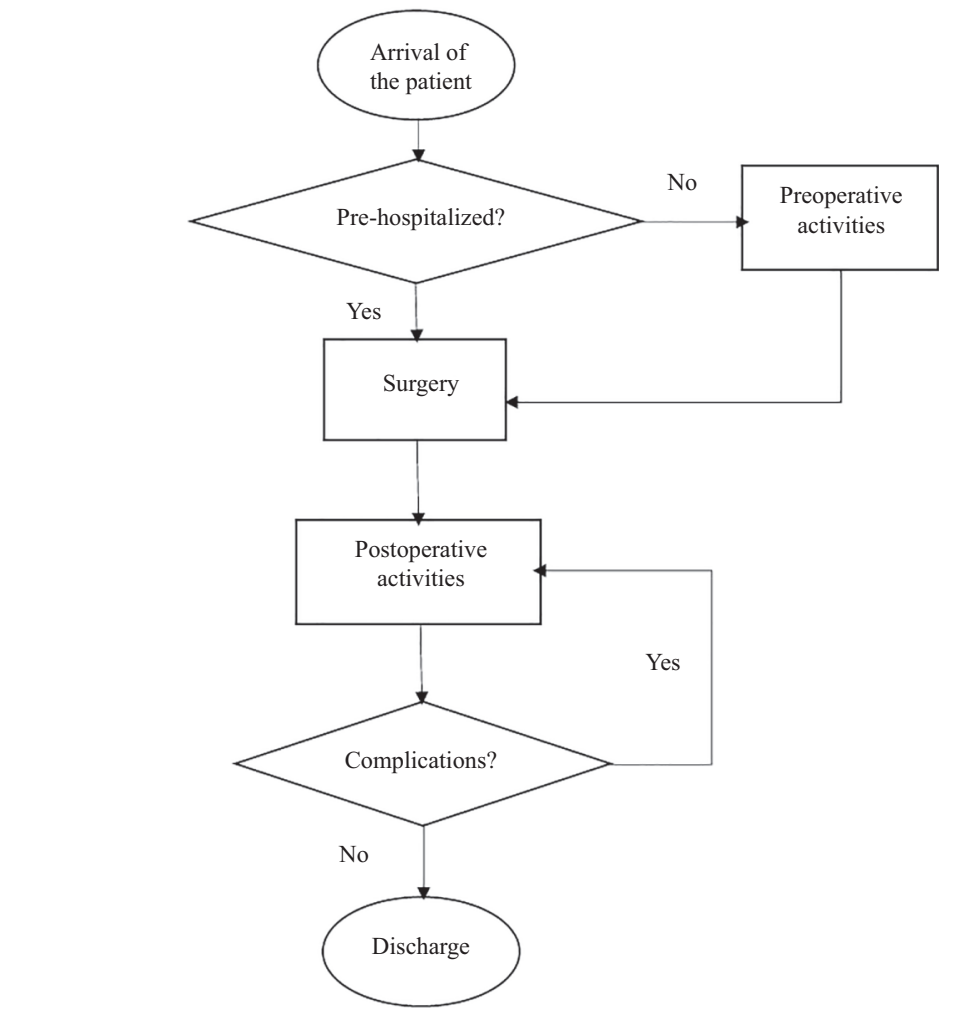

Health technology assessment through Six Sigma

1515

Figure 3.

The flow chart of the hospitalization process for patients undergoing oncologic surgery at the Maxillofacial Department of University hospital "Federico II" 
TQM

32,6

1516

Table 1.

The analysis of potential factors influencing postoperative LOS for "Cefazolin/ Clindamycin" group

\begin{tabular}{llccc}
\hline Variable & Category & $N$ & LOS [mean \pm Dev. Std.] & $p$-value \\
\hline Surgical procedure & Removal & 20 & $14.40 \pm 5.73$ & 0.109 \\
& Removal and reconstruction & 25 & $18.20 \pm 9.02$ & \\
Flap & No & 19 & $14.63 \pm 5.79$ & 0.175 \\
& Yes & 26 & $17.88 \pm 8.98$ & \\
Lymphadenectomy & No & 28 & $15.21 \pm 7.39$ & 0.159 \\
& Yes & 17 & $18.65 \pm 8.42$ & \\
Tracheotomy & No & 34 & $15.65 \pm 8.18$ & 0.200 \\
& Yes & 11 & $19.18 \pm 6.51$ & \\
Infections & No & 41 & $15.61 \pm 7.42$ & 0.12 \\
& Yes & 4 & $25.75 \pm 7.23$ & \multirow{2}{*}{ Dehiscence } \\
& No & 37 & $15.24 \pm 7.04$ & 0.19 \\
Fistulae & Yes & 8 & $22.38 \pm 9.38$ & \multirow{2}{*}{ NA } \\
& No & 45 & $16.51 \pm 7.89$ & \\
& Yes & 0 & NA &
\end{tabular}

Note(s): NA = not applicable due to $N=0$

Mann-Whitney. In this case, Mann-Whitney tests were employed to compare the medians of the categories of the variables to test their potential influence on LOS. Some significant $p$ values were found for the variables: surgical procedure, flap, lymphadenectomy while the $p$ value of tracheotomy was near a significant value (see Table 2).

To date, a defined antibiotic protocol has not been established. The use of Clindamycin alone seems not to be enough to prevent SSIs (Penel et al., 2005; Mahesh et al., 2013; Garnier et al., 2013a, b), and in some studies it seems also to increase the incidence of SSIs. The guidelines suggest the use of a first-second-generation cephalosporin with metronidazole and Clindamycin in case of allergy to penicillin (Mahesh et al., 2013; Haidar et al., 2018). According to the University Hospital of Naples "Federico II", in 2011, the Department of Maxillofacial Surgery decided to use an association of Cefazolin (first generation of cephalosporin) and Clindamycin to cover the main bacteria responsible of SSIs.

\subsection{Improve}

In 2011, according to our hospital and scientific guidelines, an association of Cefazolin, first generation of cephalosporin, and Clindamycin was used to replace the antibiotic

Table 2.

The analysis of potential factors influencing postoperative LOS for "Ceftriaxone" group

\begin{tabular}{|c|c|c|c|c|}
\hline Variable & Category & $N$ & LOS [mean \pm Dev. Std. $]$ & $p$-value \\
\hline \multirow[t]{2}{*}{ Surgical procedure } & Removal & 41 & $8.44 \pm 7.49$ & \multirow[t]{2}{*}{0.003} \\
\hline & Removal and reconstruction & 7 & $17.43 \pm 8.94$ & \\
\hline \multirow[t]{2}{*}{ Flap } & No & 41 & $8.44 \pm 7.49$ & \multirow[t]{2}{*}{0.003} \\
\hline & Yes & 7 & $17.43 \pm 8.94$ & \\
\hline \multirow[t]{2}{*}{ Lymphadenectomy } & No & 46 & $9.13 \pm 7.68$ & \multirow[t]{2}{*}{0.044} \\
\hline & Yes & 2 & $24.0 \pm 11.31$ & \\
\hline \multirow{2}{*}{ Tracheotomy } & No & 47 & $9.28 \pm 7.66$ & \multirow[t]{2}{*}{0.083} \\
\hline & Yes & 1 & $32.00+0.00$ & \\
\hline \multirow[t]{2}{*}{ Infections } & No & 48 & $9.75 \pm 8.26$ & \multirow[t]{2}{*}{ NA } \\
\hline & Yes & 0 & NA & \\
\hline \multirow[t]{2}{*}{ Dehiscence } & No & 48 & $9.75 \pm 8.26$ & \multirow[t]{2}{*}{ NA } \\
\hline & Yes & 0 & NA & \\
\hline \multirow[t]{2}{*}{ Fistulae } & No & 48 & $9.75 \pm 8.26$ & \multirow[t]{2}{*}{ NA } \\
\hline & Yes & 0 & NA & \\
\hline Note(s): NA = not & icable due to $N=0$ & & & \\
\hline
\end{tabular}


postoperative prophylactic protocol with Ceftriaxone, a third-generation cephalosporin, used as antibiotic protocol until that moment. The choice of this association is due to the action of these antibiotics to the main populations of bacteria of the mouth, such as MRSA (Methicillinresistant Staphylococcus Aureus), MSSA (Methicillin-sensitive Staphylococcus aureus), Gramnegative bacteria (Johnson et al., 1984; Cunha et al., 2012; Yang et al., 2013).

The association of Cefazolin and Clindamycin was administered after the surgical procedure in reason of $1 \mathrm{~g}$ of Cefazolin by intravenous route twice a day and $600 \mathrm{mg}$ of Clindamycin by intravenous route twice a day.

The antibiotic prophylactic protocol was administered daily until the day of discharge in association with postoperative wound cares. All surgical wounds of the skin were disinfected with povidone-iodine solutions, while those in the mouth were disinfected with chlorhexidine solution.

\subsection{Control}

Due to the non-normality distribution of the data, Mann-Whitney test was applied to all dichotomous groups. A boxplot (Figure 4) is a useful visual tool to check the difference between the postoperative LOS of Cefazolin/Clindamycin and the Ceftriaxone's one.

In order to guarantee long-term results, some other visual management tools could be implemented periodically, such as a run chart. Moreover, it would be important to organize some brainstorming sessions of clinicians who are the ones who really deal with patients and know which are the main problems and how new improvements could be implemented, regarding both the therapeutic and procedural side.

\section{Results}

In statistics, samples greater than 30 are usually considered enough to start an analysis because, due to the central limit theorem, a data set of 30 records could be considered normally distributed. In this research, there are 48 patients treated with Ceftriaxone and 45 patients treated with Cefazolin plus Clindamycin. Then, an overall sample of 93 subjects should be enough to perform a statistical analysis and the number of patients per group is numerically balanced to make a comparison between them. Despite considering a sample that should have been normally distributed, a Kolmogorov-Smirnov test was performed and had a $p$-value lower than 0.0001: the data were not normally distributed.

The Mann-Whitney test was, thus, employed to compare, according to each category, the LOS of patients who were treated with Cefazolin/Clindamycin with the one of patients treated with Ceftriaxone.

The results of such tests with an alpha level of 0.05 are summarized in Table 3. Overall, the difference in postoperative LOS between Cefazolin/Clindamycin and Ceftriaxone groups was statistically significant with a reduction of $40.9 \%$. All the tests were statistically significant

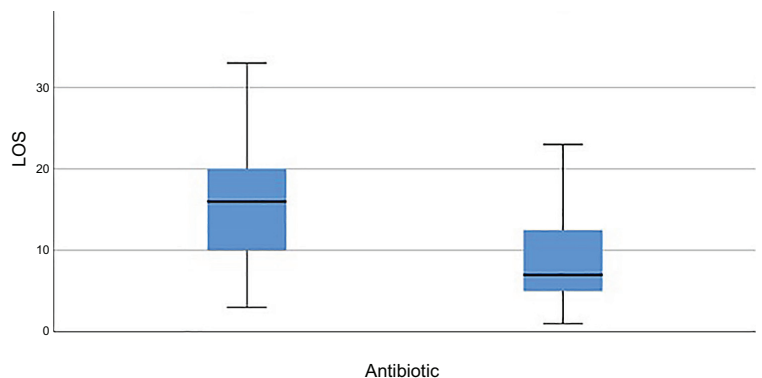

Health technology assessment through Six Sigma

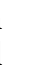


TQM

32,6

\begin{tabular}{|c|c|c|c|c|c|}
\hline Variable & Category & $\begin{array}{c}\text { Cefazolin/ } \\
\text { Clindamycin } \\
\text { [mean } \pm \text { Dev. } \\
\text { Std.] }\end{array}$ & $\begin{array}{c}\text { Ceftriaxone } \\
{[\text { mean } \pm \text { Dev. Std. }]}\end{array}$ & $\begin{array}{c}\text { Difference } \\
{[\%]}\end{array}$ & $p$-value \\
\hline All patients & & $16.51+7.89$ & $9.75+8.26$ & -40.9 & $<0.0001$ \\
\hline \multirow{2}{*}{ Surgical procedure } & Removal & $14.40 \pm 5.73$ & $8.44 \pm 7.49$ & -41.7 & $<0.0001$ \\
\hline & $\begin{array}{l}\text { Removal and } \\
\text { reconstruction }\end{array}$ & $18.20 \pm 9.02$ & $17.43 \pm 8.94$ & -4.4 & 0.929 \\
\hline \multirow[t]{2}{*}{ Flap } & No & $14.63 \pm 5.79$ & $8.44 \pm 7.49$ & -42.5 & $<0.0001$ \\
\hline & Yes & $17.88 \pm 8.98$ & $17.43 \pm 8.94$ & -2.5 & 0.983 \\
\hline \multirow[t]{2}{*}{ Cymphadenectomy } & No & $15.21 \pm 7.39$ & $9.13 \pm 7.68$ & -40.0 & $<0.0001$ \\
\hline & Yes & $18.65 \pm 8.42$ & $24.0 \pm 11.31$ & NA- & \\
\hline \multirow[t]{2}{*}{ Tracheotomy } & No & $15.65 \pm 8.18$ & $9.28 \pm 7.66$ & -40.7 & $<0.0001$ \\
\hline & Yes & $19.18 \pm 6.51$ & $32.00 \pm 0.00$ & NA- & \\
\hline \multirow[t]{2}{*}{ nfections } & No & $15.61 \pm 7.42$ & $9.75 \pm 8.26$ & -37.5 & $<0.0001$ \\
\hline & Yes & $25.75 \pm 7.23$ & $\mathrm{NA}^{*}$ & NA* & \\
\hline \multirow[t]{2}{*}{ Dehiscence } & No & $15.24 \pm 7.04$ & $9.75 \pm 8.26$ & -36.0 & $<0.0001$ \\
\hline & Yes & $22.38 \pm 9.38$ & $\mathrm{NA}^{*}$ & NA* & \\
\hline \multirow[t]{2}{*}{ Fistulae } & No & $16.51 \pm 7.89$ & $9.75 \pm 8.26$ & -40.9 & $<0.0001$ \\
\hline & Yes & $\mathrm{NA}^{*}$ & $\mathrm{NA}^{*}$ & NA* & \\
\hline
\end{tabular}

Table 3.

The complete comparative statistical analysis. Mann-

Whitney and Kruskal-

Wallis were used respectively for dichotomous groups and for age group

Note(s): NA* = not applicable since there are no cases of the category. NA- = not applicable since there few cases of one of the two categories

between the categories except for those who experience a flap ( $p$-value of 0.983 ) or underwent a removal and a reconstruction ( $p$-value of 0.929 ).

In Table 4, there are the results of a demographic study, obtained by performing a Chisquare test for each variable. Its aim was to test the difference in the compositions of the two groups according to each variable. A statistically significant difference between the occurrences of Cefazolin/Clindamycin and Ceftriaxone groups was obtained according to surgical procedure, flap, tracheotomy, infections and dehiscence. The numbers of shifts were 9 for Cefazolin/Clindamycin and 3 for Ceftriaxone, a percentage reduction of $-66.7 \%$ : despite depending on many factors, the higher number of shifts can be considered another qualitative indicator for the analysis.

Table 4.

Demographic study regarding categories of both drugs, Chi-square tests were applied

\begin{tabular}{|c|c|c|c|c|}
\hline Variable & Category & $\begin{array}{c}\text { Cefazolin/Clindamycin } \\
{[N]}\end{array}$ & Ceftriaxone $[N]$ & $p$-value \\
\hline \multirow[t]{2}{*}{ Surgical procedure } & Removal & 20 & 41 & $<0.0001$ \\
\hline & Removal and reconstruction & 25 & 7 & \\
\hline \multirow[t]{2}{*}{ Flap } & No & 19 & 41 & $<0.0001$ \\
\hline & Yes & 26 & 7 & \\
\hline \multirow[t]{2}{*}{ Lymphadenectomy } & No & 28 & 46 & $<0.0001$ \\
\hline & Yes & 17 & 2 & \\
\hline \multirow[t]{2}{*}{ Tracheotomy } & No & 34 & 47 & 0.001 \\
\hline & Yes & 11 & 1 & \\
\hline \multirow[t]{2}{*}{ Infections } & No & 41 & 48 & 0.035 \\
\hline & Yes & 4 & 0 & \\
\hline \multirow[t]{2}{*}{ Dehiscence } & No & 37 & 48 & 0.002 \\
\hline & Yes & 8 & 0 & \\
\hline \multirow{2}{*}{ Fistulae } & No & 45 & 48 & NA \\
\hline & Yes & 0 & 0 & \\
\hline
\end{tabular}




\section{Discussion and conclusion}

Danner et al. proved that AHP can be used in HTA to give a quantitative dimension to patients' preferences for treatment endpoints (Danner et al., 2011). Substantially, they used a quantitative method, the AHP, like a tool to extract quantitative information in an HTA study. Similarly to the AHP, the SS method has already proved its feasibility in the past years in many works (Improta et al., 2015, 2019), and this is testified also by recent reviews (Henrique and Godinho Filho, 2020), but there are no examples of this methodology used as a tool of HTA for drugs (antibiotics in this paper). That's where the novelty of this paper relies: using the mathematical and statistical rigor of the SS method and the DMAIC problemsolving strategy to perform a part of HTA studies, the analysis of the clinical variables. When considering the other aspects of HTA, the two drugs are equally approved, have similar costs and are both currently in the clinical practice without requiring different organizational pathways. The results showed that all the aims of the SS project were achieved: a lower postoperative LOS was found in a statistically significant way, the number of shifts was identified in the groups so as the number of the overall complications (infections, dehiscence, fistulae, flap). Thus, the paper contributes to the improvement of patients' outcome as well as to the hospital management of patients, since the reduction of hospital-acquired infections is a central theme in literature (Kuwaiti and Subbarayalu, 2017; Montella et al., 2017).

When analysing infective complications, it is likely to assume that they are controlled by the only antibiotic therapy because broad-spectrum antibiotics were employed: they act on different kinds of bacteria. Moreover, it is likely to assume that the infections were contracted during the surgery. A bacterial resistance screening should be performed in a preoperative phase, but the protocols do not require it. This happens because a screening of the bacteria can be made only when the infection is developed on material picked up from the infected site. Cardiovascular diseases, diabetes, age should not act on the action of the antibiotics.

From the analysis of the data shown in Table 3 , the LOS of patients undergoing head and neck cancer surgery on bone tissues is considerably reduced in the group treated with Ceftriaxone. This can be related to a decrease of complication in the postoperative period. Postoperative complications increase the LOS and the costs of hospitalization because a major need of care is required for the patient to guarantee a good outcome of the surgery. Considering all patients that entered the study, a decrease in the LOS of $40.9 \%$ is observed in the group treated with Ceftriaxone compared to the one treated with Cefazolin and Clindamycin. Concerning the analysis of LOS in relation with the type of surgical procedure, in Table 3 two different results are shown. A minor LOS is observed in the group of patients treated with Ceftriaxone that underwent cancer removal ( $-41.7 \%$ compared to the Cefazolin and Clindamycin group). Simple cancer removal without reconstruction determines a minor development of SSIs. This happens because, as explained in the introduction, this kind of procedure is often reserved to those small and early-staged malignant tumors that just need slight asportation of the tissues. Analysing patients undergoing head and neck cancer surgery on bone tissues with tissue removal and reconstruction, no significant difference in LOS was found ( $\phi$-value 0.929): big tissue removals need a reconstruction to restore the anatomical and functional loss and, to guarantee this restoration, pedicled or free flaps are needed. These flaps, usually coming from different parts of the body, specifically from fibula, influence the outcomes of surgery because of the intrinsic problems related to a demolition and reconstructive surgery, with a major incidence of surgical complications, such as haematoma, haemorrhage, ischaemia of the flap. Moreover, the use of a different part of the body to reconstruct face defect leads to the increase of infection because of the presence of non-resident microflora on the flap. Especially when pedicled or free flaps are used to reconstruct defect of the mouth, the presence of resident and non-resident microflora increases the incidence of infections that can lead to SSIs if not adequately treated.
Health technology assessment through Six Sigma

1519 
TQM

32,6

Future developments for this paper could be the analysis of the follow-up for these patients, where applicable considering the lethal pathology in analysis, in order to observe a longer time of efficacy of the drug. In this paper only surgical variables and complications were considered, but also clinical and anamnestic variables could be analysed. Despite having similar costs, a cost-effectiveness analysis on these antibiotics could be another future work for this kind of problems in order to fully understand the most convenient antibiotic prophylaxis. Moreover, considering the previous discussion on the methodology, SS could be employed as a new tool of HTA to make a part of its reports regarding more clinical sides.

\subsection{Practical implications}

The results obtained by this paper enhance the evident reduction in postoperative LOS and complications for patients undergoing oncologic surgery when administering Ceftriaxone antibiotic. Similarly to previous works (Al Kuwaiti and Subbarayalu, 2017; Montella et al., 2017), the decrease in the number of flaps, dehiscence, infections and fistulae would consist in a great benefit from both hospital and patients' perspective. The managers of hospital could consider employing Ceftriaxone to tackle the big issue of comorbidities and infections in the health facilities overcoming the problem of financial loss due to the prolongation of patients' postoperative LOS. Therefore, the public service for patients would have an evident quality improvement, as per SS methodology.

\section{Note}

1. International Agency for Research on Cancer/World Health Organization. http:/globocan.iarc.fr/ Pages/fact_sheets_can-cer.aspx>.

\section{References}

Adikorley, R.D., Rothenberg, L. and Guillory, A. (2017), "Lean Six Sigma applications in the textile industry: a case study", International Journal of Lean Six Sigma, Vol. 8 No. 2, pp. 210-224.

Al Kuwaiti, A. and Subbarayalu, A.V. (2017), "Reducing hospital-acquired infection rate using the Six Sigma DMAIC approach”, Saudi Journal of Medicine and Medical Sciences, Vol. 5, p. 260.

Al Kuwaiti, A. (2016), "Application of six sigma methodology to reduce medication errors in the outpatient pharmacy unit: a case study from the king Fahd university hospital, Saudi Arabia", International Journal of Quality Research, Vol. 10 No. 2, pp. 267-278.

Alhamali, R.M. (2019), "Success factors and benefits of six sigma implementation in hospitals: a systematic review", Business Management Studies, Vol. 5, pp. 1-10, .

Allen, T.T., Tseng, S.-H., Swanson, K. and McClay, M.A. (2009), "Improving the hospital discharge process with six sigma methods", Quality Engineering, Vol. 22, pp. 13-20, doi: 10.1080/ 08982110903344812.

Arafeh, M., Barghash, M.A., Haddad, N., Musharbash, N., Nashawati, D., Al-Bashir, A. and Assaf, F. (2018), "Usingsix sigma DMAIC methodology and discrete event simulation to reduce patient discharge time in king Hussein cancer center", Journal of Healthcare Engineering, doi: 10.1155/ 2018/3832151, 2018, p. 3832151.

Bakar, F.A.A., Subari, K. and Daril, M.A.M. (2015), "Critical success factors of lean Six Sigma deployment: a current review", International Journal of Lean Six Sigma, Vol. 6 No. 4, pp. 339-348.

Barrios, M.A.O. and Jiménez, H.F. (2016), "Use of six sigma methodology to reduce appointment leadtime in obstetrics outpatient department”, Journal of Medical Systems, Vol. 40, p. 220. 
Battista, R.N. and Hodge, M.J. (1999), "The evolving paradigm of health technology assessment: reflections for the millennium”, CMAJ: Canadian Medical Association Journal, Vol. 160 No. 10, p. 1464.

Becker, G.D., Parell, G.J., Busch, D.F., Finegold, S.M. and Acquarelli, M.J. (1978), "Anaerobic and aerobic bacteriology in head and neck cancer surgery”, Archives of Otolaryngology, Vol. 104 No. 10 , pp. 591-594.

Besseris, G. (2014), "Multi-factorial lean Six Sigma product optimization for quality, leanness and safety", International Journal of Lean Six Sigma, Vol. 5 No. 3, pp. 253-278.

Health technology assessment through Six Sigma

1521

Chaturvedi, A.K., Anderson, W.F., Lortet-Tieulent, J., Curado, M.P., Ferlay, J., Franceschi, S., Rosenberg, P.S., Bray, F. and Gillison, M.L. (2013), "Worldwide trends in incidence rates for oral cavity and oro-pharyngeal cancers", Journal of Clinical Oncology, Vol. 31, pp. 4550-9.

Chuang, S.C., Jenab, M., Heck, J.E., Bosetti, C., Talamini, R., Matsuo, K. and La Vecchia, C. (2012), "Diet and the risk of head and neck cancer: a pooled analysis in the INHANCE consortium", Cancer Causes Control, Vol. 23 No. 1, pp. 69-88.

Chugani, N., Kumar, V., Garza-Reyes, J.A., Rocha-Lona, L. and Upadhyay, A. (2017), "Investigating the green impact of lean, Six Sigma and lean Six Sigma. A systematic literature review", International Journal of Lean Six Sigma, Vol. 8 No. 1, pp. 7-32.

Converso, G., Improta, G., Mignano, M. and Santillo, L.C. (2015), "A simulation approach for agile production logic implementation in a hospital emergency unit", in International Conference on Intelligent Software Methodologies, Tools, and Techniques, Springer, pp. 623-634.

Cunha, T.F., Melancia, T.A., Ribeiro, C.M., de Brito, J.A., Miguel, S.S. and do Casal, D.A. (2012), "Risk factors for surgical site infection in cervico-facial oncological surgery", Journal of CranioMaxillo-Facial Surgery, Vol. 30, pp. 443-448.

D'Addio, G., Ricciardi, C., Improta, G., Bifulco, P. and Cesarelli, M. (2020), "Feasibility of machine learning in predicting features related to congenital nystagmus", Paper presented at the IFMBE Proceedings, Vol. 76, pp. 907-913, doi: 10.1007/978-3-030-31635-8_110.

Danner, M., Hummel, J.M., Volz, F., et al. (2011), "Integrating patients' views into health technology assessment: analytic hierarchy process (AHP) as a method to elicit patient preferences", International Journal of Technology Assessment in Health Care, Vol. 27 No. 4, pp. 369-375, doi: 10.1017/S0266462311000523.

Durand, M.L., Yarlagadda, B.B., Rich, D.L., Lin, D.T., Emerick, K.S., Rocco, J.W. and Deschler, D.G. (2015), "The time course and microbiology of surgical site infections after head and neck free flap surgery”, Laryngoscope, Vol. 125 No. 5, pp. 1084-1089.

El-Eid, G.R., Kaddoum, R., Tamim, H. and Hitti, E.A. (2015), "Improving hospital discharge time: a successful implementation of six sigma methodology", Medicine (Baltimore), Vol. 94 No. 12, p. e633, doi: 10.1097/MD.0000000000000633.

Favaretti, C., Cicchetti, A., Guarrera, G., Marchetti, M. and Ricciardi, W. (2009), "Health technology assessment in Italy", International Journal of Technology Assessment in Health Care, Vol. 25 No. S1, pp. 127-133.

Feng, Q. and Manuel, C.M. (2008), "Under the knife: a national survey of six sigma programs in US healthcare organizations", International Journal of Health Care Quality Assurance, Vol. 21, pp. 535-547, doi: 10.1108/09526860810900691.

Fillingham, D. (2008), Lean Healthcare: Improving the Patient's Experience, Kingsham Press, Chichester, Vol. 26.

Freitas, J.G. and Costa, H.G. (2017), "Impacts of lean Six Sigma over organizational sustainability a systematic literature review on scopus base", International Journal of Lean Six Sigma, Vol. 8 No. 1, pp. 89-108.

Garnier, M., Blayau, C., Fulgencio, J.-P., Baujat, B., Arlet, G., Bonnet, F. and Quesnel, C. (2013a), "Rational approach of antibioprophylaxis: a systematic review in ENT cancer surgery", AnnalesFrançaises D’Anesthèsie et de Réanimation, Vol. 32, pp. 315-324. 
TQM 32,6

Garnier, M., Blayau, C., Fulgencio, J.-P., Baujat, B., Arlet, G., Bonnet, F. and Quesnel, C. (2013b), "Rational approach of antibioprophylaxis: a systematic review in ENT cancer surgery", AnnalesFrançaises D’Anesthèsie et de Réanimation, Vol. 32, pp. 315-324.

Haidar, Y.M., Tripathi, P.B., Tjoa, T., Walia, S., Zhang, L., Chen, Y., Nguyen, D.V., Mahdoubi, H., Armstrong, W.B. and Goddard, J.A. (2018), "Antibiotic prophylaxis in clean contaminated head and neck cases with microvascular free flap reconstruction: a systematic review and metaanalysis", Head Neck, Vol. 40 No. 2, pp. 417-427.

Hashibe, M., Brennan, P., Chuang, S.C., Boccia, S., Castellsague, X., Chen, C. and Fernandez, L. (2009), "Interaction between tobacco and alcohol use and the risk of head and neck cancer: pooled analysis in the International Head and Neck Cancer Epidemiology Consortium", Cancer Epidemiol Biomarkers Prev., American Association for Cancer Research, Vol. 18 No. 2, pp. 541-550.

Henrique, D.B. and Godinho Filho, M. (2020), "A systematic literature review of empirical research in Lean and Six Sigma in healthcare", Total Quality Management and Business Excellence, Vol. 31 Nos 3-4, pp. 429-449.

Horan, T.C., Gaynes, R.P., Martone, W.J., Jarvis, W.R. and Emori, T.G. (1992), “CDC definitions of nosocomial surgical site infections, 1992: a modification of CDC definitions of surgical wound infections", AM J Infect Control, Vol. 20 No. 5, pp. 271-274.

Improta, G., Balato, G., Romano, M., Carpentieri, F., Bifulco, P., Russo, M.A., Rosa, D., Triassi, M. and Cesarelli, M. (2015), "Lean Six Sigma: a new approach to the management of patients undergoing prosthetic hip replacement surgery", Journal of Evaluation in Clinical Practice, Vol. 21 No. 4, pp. 662-672, doi: 10.1111/jep.12361.

Improta, G., Balato, G., Romano, M., Ponsiglione, A.M., Raiola, E., Russo, M.A., Cuccaro, P., Santillo, L.C. and Cesarelli, M. (2017), "Improving performances of the knee replacement surgery process by applying DMAIC principles", Journal of Evaluation in Clinical Practice, Vol. 23 No. 6, pp. 1401-1407, doi: 10.1111/jep.12810.

Improta, G., Cesarelli, M., Montuori, P., Santillo, L.C. and Triassi, M. (2018a), "Reducing the risk of healthcare-associated infections through lean six sigma: the case of the medicine areas at the Federico II university hospital in Naples (Italy)", Journal of Evaluation in Clinical Practice, Vol. 24 No. 2, pp. 338-346, doi: 10.1111/jep.12844.

Improta, G., Romano, M., Di Cicco, M.V., Ferraro, A., Borrelli, A., Verdoliva, C., Triassi, M. and Cesarelli, M. (2018b), "Lean thinking to improve emergency department throughput at AORN Cardarelli hospital”, BMC Health Services Research, Vol. 18 No. 1, p. 914, doi: 10.1186/s12913018-3654-0.

Improta, G., Russo, M.A., Triassi, M., Converso, G., Murino, T. and Santillo, L.C. (2018c), "Use of the AHP methodology in system dynamics: modelling and simulation for health technology assessments to determine the correct prosthesis choice for hernia diseases", Mathematical Biosciences, Vol. 299, pp. 19-27, doi: 10.1016/j.mbs.2018.03.004.

Improta, G., Ricciardi, C., Borrelli, A., D’alessandro, A., Verdoliva, C. and Cesarelli, M. (2019), "The application of six sigma to reduce the pre-operative length of hospital stay at the hospital Antonio Cardarelli”, International Journal of Lean Six Sigma, Vol. 11 No. 3, pp. 555-576, doi: 10.1108/IJLSS-02-2019-0014.

Improta, G., Balato, G., Ricciardi, C., Russo, M.A., Santalucia, I., Triassi, M. and Cesarelli, M. (2019a), "Lean Six Sigma in healthcare: fast track surgery for patients undergoing prosthetic hip replacement surgery", TQM J, Vol. 31 No. 4, pp. 526-540, doi: 10.1108/TQM10-2018-0142.

Improta, G., Perrone, A., Russo, M.A. and Triassi, M. (2019b), "Health technology assessment (HTA) of optoelectronic biosensors for oncology by analytic hierarchy process (AHP) and Likert scale", BMC Medical Research Methodology, Vol. 19 No. 1, p. 140.

Improta, G., Guizzi, G., Ricciardi, C., Giordano, V., Ponsiglione, A.M., Converso, G. and Triassi, M. (2020), "Agile six sigma in healthcare: case study at Santobono pediatric hospital", International Journal of Environmental Research and Public Health, Vol. 17 No. 3, p. 1052. 
Johnson, J.T., Yu, V.L., Myers, E.N., Murder, R.R., Thearle, P.B. and Diven, W.F. (1984), "Efficacy of two third generation of cephalosporins in prophylaxis for head and neck surgery", Archives of Otolaryngology, Vol. 110 No. 4, pp. 224-227.

Kalra, J. and Kopargaonkar, A. (2016), "Quality improvement in clinical laboratories: a six sigma concept”, Patholoty Laboratory Medicine, Vol. 1 No. 1, pp. 11-20.

Health technology assessment through Six Sigma

Kamizono, K., Sakuraba, M., Nagamatsu, S., Miyamoto, S. and Hayashi, R. (2014), "Statistical analysis of surgical site infection after head and neck reconstructive surgery", Annals of Surgical Oncology, Vol. 21 No. 5, pp. 1700-1705.

Karakida, K., Sakamoto, H., Aoki, T., Ota, Y., Yamazaki, H., Otsuru, M., Takahashu M. and Miyasaka, M. (2010), "Analysis of risk factors for surgical site infections in 276 oral cancer surgeries with microvascular free flap reconstructions at a single university hospital", Journal of Infection and Chemotherapy, Vol. 16, pp. 334-339.

Khan, Z., Tönnies, J. and Müller, S. (2014), "Smokeless tobacco and oral cancer in South Asia: a systematic review with meta-analysis", Journal of Cancer Epidemiol, Hindawi, p. 201. doi: 10. 1155/2014/394696.

Koning, H.de, Verver, J.P.S., Heuvel, J. van den, Bisgaard, S. and Does, R.J.M.M. (2006), "Lean six sigma in healthcare", Journal for Healthcare Quality, Vol. 28, pp. 4-11, doi: 10.1111/j.1945-1474.2006. tb00596.x.

Lester, S. and Yang, W.Y. (2012), "Principles and management of head and neck cancer", Surgery (Oxford), Vol. 30, pp. 617-623.

Loftus, K., Tilley, T., Hoffman, J., Bradburn, E. and Harvey, E. (2015), "Use of Six Sigma strategies to pull the line on central line-associated bloodstream infections in a neurotrauma intensive care unit", Journal of Trauma Nursing, Vol. 22, pp. 78-86.

Mahesh, C.B., Ramakant, B.K. and Jagadeesh, V.S. (2013), "The prevalence of inducible and constitutive clindamycin resistance among the nasal isolates of staphylococci", Journal of Clinical and Diagnostic Research, Vol. 7, pp. 1620-1622.

Montella, E., Di Cicco, M.V., Ferraro, A., Centobelli, P., Raiola, E., Triassi, M. and Improta, G. (2017), "The application of Lean Six Sigma methodology to reduce the risk of healthcare-associated infections in surgery departments", Journal of Evaluation in Clinical Practice, Vol. 23 No. 3, pp. 530-539, doi: 10.1111/jep.12662.

Ogihara, H., Takeuchi, K. and Majima, Y. (2009), "Risk factors of postoperative infection in head and neck surgery", Auris Nasus Larynx, Vol. 36 No. 4, pp. 457-60.

Penel, N., Fournier, C., Lefebvre, D. and Lefebvre, J.L. (2005), "Multivariate analysis ofrisk factors for wound infection in head and neck squamous cell carcinoma surgery with opening of mucosa. Study of 260 procedures", Oral Oncology, Vol. 41, pp. 35-44.

Radoï, L. and Luce, D. (2013), "A review of risk factors for oral cavity cancer: the importance of a standardized case definition”, Community Dentistry and Oral Epidemiology, Vol. 41 No. 2, pp. 97-109.

Recenti, M., Ricciardi, C., Gìslason, M., Edmunds, K., Carraro, U. and Gargiulo, P. (2020), "Machine learning algorithms predict body mass index using nonlinear trimodal regression analysis from computed tomography scans", Paper presented at the IFMBE Proceedings, Vol. 76, pp. 839-846, doi: 10.1007/978-3-030-31635-8_100.

Ribeiro, K.B., Levi, J.E., Pawlita, M., Koifman, S., Matos, E., Eluf-Neto, J. and Waterboer, T. (2011), "Low human papilloma virus prevalence in head and neck cancer: results from two large casecontrol studies in high-incidence regions", International Journal of Epidemiology, Vol. 40, pp. 489-502.

Ricciardi, C., Fiorillo, A., Valente, A.S., Borrelli, A., Verdoliva, C., Triassi, M. and Improta, G. (2019), "Lean Six Sigma approach to reduce LOS through a diagnostic-therapeutic-assistance path at A.O.R.N. A. Cardarelli”, The TQM Journal, Vol. 31 No. 5, pp. 657-672, doi: 10.1108/TQM-022019-0065. 
TQM 32,6

Ricciardi, C., Balato, G., Romano, M., Santalucia, I., Cesarelli, M. and Improta, G. (2020), "Fast track surgery for knee replacement surgery: a lean six sigma approach", The TQM Journal, Vol. 32 No. 3, pp. 461-474, doi: 10.1108/TQM-06-2019-0159.

Romano, M., Bifulco, P., Ponsiglione, A.M., Gargiulo, G.D., Amato, F. and Cesarelli, M. (2018), "Evaluation of floatingline and foetal heart rate variability", Biomedical Signal Processing and Control, Vol. 39, pp. 185-196, doi: 10.1016/j.bspc.2017.07.018.

Rotundo, L.D.B., Toporcov, T.N., Biazevic, G.H., Carvalho, M.B.D., Kowalski, L.P. and Antunes, J.L.F. (2013), "Are recurrent denture-related sores associated with the risk of oral cancer? A case control study", Revista Brasileira de Epidemiologia, Vol. 16 No. 3, pp. 705-15.

Russel, M.D. and Goldberg, A.N. (2012), "What is the evidence for the use of prophylactic antibiotics in clean-contaminated head and neck surgery?”, Laryngoscope, Vol. 122, pp. 945-946.

Şahbaz, I., Taner, M.T., Eliaçı, M., Kağan, G., Erbaş, E. and Enginyurt, H. (2014), "Adoption of Six Sigma's DMAIC to reduce complications in IntraLase surgeries", International Journal of Statistics in Medical Research, Vol. 3, pp. 126-133, .

Samman, M., Wood, H., Conway, C., Berri, S., Pentenero, M., Gandolfo, S. and Rabbitts, P. (2014), "Next generation sequelling analysis for detecting human papilloma virus in oral verrucous carcinoma”, Oral Surg Oral Med Oral Pathol Oral Radiol, Vol. 118 No. 1, pp. 117-125.e1.

Saulle, R., Semyonov, L., Mannocci, A., Careri, A., Saburri, F., Ottolenghi, L., Guerra, F. and La Torre, G. (2015), "HPV and cancerous diseases of the head and neck: a systematic review and metaanalysis", Oral Diseases, Vol. 21 No. 4, pp. 417-431.

Steere, L., Rousseau, M. and Durland, L. (2018), "Lean six sigma for intravenous therapy optimization: a hospital use of lean thinking to improve occlusion management", Journal of the Association for Vascular Access, Vol. 23, pp. 42-50, doi: 10.1016/j.java.2018.01.002.

Tachezy, R., Klozar, J., Rubenstein, L., Smith, E., Saláková, M., Šmahelová, J., Ludvíková, V., Rotnáglová, E., Kodet, R. and Hamšíková, E. (2009), "Demographic and risk factors in patients with head and neck tumors", Journal of Medical Virology, Vol. 81 No. 5, pp. 878-87.

Van Den Heuvel, J., Does, R.J.M.M. and Verver, J.P.S. (2005), "Six Sigma in healthcare: lessons learned from a hospital", International Journal of Six Sigma and Competitive Advantage, Vol. 1, pp. 380-388, doi: 10.1504/IJSSCA.2005.008504.

Van Den Heuvel, J., Does, R.J.M.M. and De Koning, H. (2006), "Lean six sigma in a hospital", International Journal of Six Sigma and Competitive Advantage, Vol. 2, pp. 377-388, doi: 10.1504/ IJSSCA.2006.011566.

Vijay, S.A. (2014), "Reducingand optimizing the cycle time of patients discharge process in A hospital using six sigma dmaic approach", International Journal of Quality Research, Vol. 8 No. 2, pp. 169-182.

Vrijens, B. (2019), "A Six Sigma framework to successfully manage medication adherence”, British Journal of Clinical Pharmacology, Vol. 85, pp. 1661-1663, doi: 10.1111/bcp.13905.

Walter, O. and Paladini, E. (2019), "Lean six sigma in Brazil: a literature review”, International Journal of Lean Six Sigma, Vol. 10 No. 1, pp. 435-472, doi: 10.1108/IJLSS-09-2017-0103.

Yang, C.H., Chew, K.Y., Solomkin, J.S., Lin, P.Y., Chiang, Y.C. and Kuo, Y.R. (2013), "Surgical site infections among high-risk patients in clean-contaminated head and neck reconstructive surgery: concordance with preoperative oral flora”, Annals of Plastic Surgery, Vol. 71, pp. S55-S60.

\section{Corresponding author}

Giovanni Improta can be contacted at: ing.improta@gmail.com

For instructions on how to order reprints of this article, please visit our website:

www.emeraldgrouppublishing.com/licensing/reprints.htm

Or contact us for further details: permissions@emeraldinsight.com 